\title{
Paper-based microfluidic biofuel cell operating under glucose concentrations within physiological range
}

Maria José González-Guerrero, ${ }^{* a}$ F. Javier del Campo, ${ }^{a}$ Juan Pablo Esquivel, ${ }^{\mathrm{a}, \mathrm{b}}$ Dónal Leech ${ }^{\mathrm{c}}$ and Neus Sabaté

${ }^{a}$ Instituto de Microelectrónica de Barcelona, IMB-CNM (CSIC), Campus de la Universidad Autónoma de Barcelona (Esfera UAB), 08193-Bellaterra, Barcelona, España. E-mail: javier.delcampo@csic.es; neus.sabate@imb-cnm.csic.es; Fax: +34 935801496; Tel: +34 935947700.

${ }^{b}$ Department of Bioengineering, University of Washington, 3720 15th Ave NE Seattle, WA 98195-5061, USA.

${ }^{c}$ School of Chemistry and Ryan Institute, National University of Ireland, Galway, Ireland. E-mail: donal.leech@nuigalway.ie.

d.Institució Catalana de Recerca i Estudis Avançats (ICREA), Barcelona, Spain.

*Corresponding author. Maria José González-Guerrero. Tel: +34 93 5947700; Fax: +34 935801496. E-mail address: mariajose.gonzalez@imb-cnm.csic.es. Postal address: Instituto de Microelectrónica de Barcelona, IMBCNM (CSIC), Campus de la Universidad Autónoma de Barcelona (Esfera UAB), 08193-Bellaterra, Barcelona, España

\begin{abstract}
This work addresses the development of a compact paper-based enzymatic microfluidic glucose $/ \mathrm{O}_{2}$ fuel cell that can operate using a very limited sample volume $(\approx 35 \mu \mathrm{l})$ and explores the energy generated by glucose at concentrations typically found in blood samples at physiological conditions $(\mathrm{pH}$ 7.4). Carbon paper electrodes combined with a paper sample absorption substrate all contained within a plastic microfluidic casing are used to construct the paper-based fuel cell. The anode catalysts consist of glucose dehydrogenase and $\left[\mathrm{Os}\left(4,4^{\prime}-\right.\right.$ dimethoxy-2,2'-bipyridine) ${ }_{2}$ (poly-vinylimidazole) $\left.{ }_{10} \mathrm{Cl}\right]^{+}$as mediator, while the cathode catalysts were bilirubin oxidase and $\left.\left[\mathrm{Os}\left(2,2^{\prime} \text {-bipyridine }\right)_{2} \text { (poly-vinylimidazole }\right)_{10} \mathrm{Cl}\right]^{+}$as mediator.

The fuel cell delivered a linear power output response to glucose over the range of $2.5 \mathrm{mM}$ to $30 \mathrm{mM}$, with power densities ranging from 20 to $90 \mu \mathrm{W} \mathrm{cm}$. The quantification of the available electrical power as well as the energy density extracted from small synthetic samples allows
\end{abstract}


planning potential uses of this energy to power different sensors and analysis devices in a wide variety of in-vitro applications.

\section{Keywords}

Paper-based biofuel cell

Enzymatic

Microfluidic

\section{Introduction}

The need for alternative energy sources, able to produce clean electricity, has stimulated the investigation of new portable sources of sustainable and renewable energy production during the last couple of decades. In this respect, research in enzymatic fuel cells (EFC) has been encouraged due to their unique advantages over metal-based conventional fuel cells; namely, their environmental friendly nature related to their biological origin and their capability of working with very mild chemical reactants. However, despite the notable improvements performed in the increase of enzymatic catalytic activity and the electronic transfer to the fuel cell electrodes, enzyme fuel cells still lack of the required stability and lifetime to be considered a solid candidate for clean energy production.

Another major motivation for the development of enzymatic fuel cells (Luckarift et al., 2014) concerns to the production of electricity from glucose available in human physiological fluids, e.g. blood, plasma, saliva, tears and urine (Falk et al., 2014, Milton et al., 2015, $\underline{\text { Bandodkar and }}$ Wang, 2016 and Conghaile et al., 2016). The possibility of envisaging the use of the enzymatic fuel cells as power sources for implantable devices has generated a lot of research efforts in the last decade. Despite the progress in this direction (Katz and MacVittie, 2013), to the best of our knowledge, implantable fuel cells have shown to be unable to work for more than a few days.

Lately, biofuel cells have found a very interesting applications niche in in-vitro applications. In this scenario, they would generate energy to power small biodevices using the electrical power extracted from the same sample to be analyzed (Bullen et al., 2006; Pinyou et al., 2015; Zhou, 2015). This turns to be particularly interesting for paper-based analytical devices (Yetisen et al., $\underline{2013}$ ), in which an integrated power source would enable to obtain unambiguous results without external instrumentation. In fact, paper has been applied as a substrate to develop power sources 
and batteries before (Sharifi et al., 2015). Among them, enzymatic fuel cells appear to be one of the most suitable power sources for paper-based devices in terms of environmental impact (Nguyen et al., 2014). Paper allows the confinement of liquids to specified regions and can wick fluids via capillary action allowing passive liquid transport (Osborn et al., 2010; Thom et al., 2013; Cate et al., 2014). Moreover, enzymatic paper-based devices have been identified as especially suitable for point-of-care purposes in the field of home health-care settings and for implementation in developing countries (Dungchai et al., 2009; Martinez et al., 2009; Nie et al., $\underline{2010})$.

Since their early appearance, the development of these microfluidic platforms was centered on the enhancement of analytical performance attained by system miniaturization (Meredith and Minteer, 2012). One way of increasing the integration level of these enzymatic paper-based systems is through immobilization of catalysts at the electrode surfaces. Catalysis in an EFC is achieved usually by a specific enzyme, with electron transfer between enzyme and electrode mediated by a redox species, so if these are immobilized on the electrode surface the cost involved in the power generation is minimized. Furthermore, enzymatic lifetime improved using immobilized catalysts.

In general, the power output generated by an EFC can be raised if porous electrode structures, that support fuel transport to the reaction sites, are used (Kim et al., 2006; Wen and Eychmüller, 2016). Therefore, the strategies followed by researchers have been focused on increasing the electrode reactive surface area and on optimizing an efficient charge transfer mechanism between the liquid phase, the catalytic solution and the electrode surface inside the system (MacAodha et al., 2012).

The enzymes are chosen depending on the characteristics required. Among the enzymes performing oxidation of glucose at the anode, FAD-dependent glucose dehydrogenase (GDH) is widely employed because it is unaffected by molecular oxygen present in solution (Tsujimura et al., 2006; Moehlenbrock et al., 2011). Regarding the electro-reduction of oxygen to water at the cathode the most reported enzyme is bilirubin oxidase (BOx), very suitable for applications requiring $\mathrm{pH}$ close to neutrality (Ivanov et al., 2010). Selection of redox mediator or appropriate redox potential and structure can enhance electron transfer between enzyme and electrode. Since 
the initial report on the use of ferrocene and its derivatives (Cass et al., 1984), osmium-based redox polymers have been widely utilized in enzymatic devices (Aquino Neto and De Andrade, 2013). Osmium redox polymer mediators have the flexibility that their redox potential can be tailored conveniently by altering the ligands attached to the osmium central metal atom (Forster and Vos, 1990, Gallaway and Calabrese Barton, 2008 and Sakai et al., 2009) giving a broad voltage range that makes them suitable for both anode and cathode processes in glucose/ $\mathrm{O}_{2}$ enzymatic fuel cells (Rengaraj et al., 2011; Osadebe et al., 2015).

With the aim of approaching enzymatic fuel cells to a practical application, we report the development of a compact paper-based enzymatic microfluidic glucose $/ \mathrm{O}_{2}$ fuel cell that is operated with a small sample volume at blood glucose concentration levels. In view of its applicability to real samples, the volume required to feed the device has been restricted to only $35 \mu \mathrm{l}$, a volume easily obtained from a finger prick. This was carried out using a flexible and lightweight device fabricated using laminated plastic materials with a paper-based core.

\section{Materials and methods}

\subsection{Electrolyte and fuel}

All chemicals and biochemicals were, unless otherwise stated, purchased from Sigma-Aldrich. Phosphate buffer at pH 7.4 was utilized in all the studies. It was prepared by the combination of; sodium phosphate monobasic dihydrate $\left(\mathrm{NaH}_{2} \mathrm{PO}_{4} \cdot 2 \mathrm{H}_{2} \mathrm{O}\right)$, sodium phosphate dibasic dihydrate $\left(\mathrm{Na}_{2} \mathrm{HPO}_{4} \cdot 2 \mathrm{H}_{2} \mathrm{O}\right)$ and sodium chloride $(\mathrm{NaCl})$ for a final $100 \mathrm{mM}$ concentration. The $\mathrm{pH}$ of this solution was then adjusted adding $\mathrm{NaH}_{2} \mathrm{PO}_{4} \cdot 2 \mathrm{H}_{2} \mathrm{O}$ for lower or $\mathrm{Na}_{2} \mathrm{HPO}_{4} \cdot 2 \mathrm{H}_{2} \mathrm{O}$ for raising the $\mathrm{pH}$.

The fuel used in the experiments was $\alpha-\mathrm{D}(+)$-glucose prepared in a stock solution of $1 \mathrm{M}$ at least $24 \mathrm{~h}$ before its use to establish the anomeric equilibrium between $\alpha$ and $\beta$ forms of D-glucose. This prepared glucose was kept in the refrigerator at $4{ }^{\circ} \mathrm{C}$ and used within a week.

Fuel cell measurements were conducted with a $\mathrm{CH}$ Instruments electrochemical workstation model 650A (Austin TX) controlled through a personal computer, and all the experiments were carried out at room temperature. 


\subsection{Enzymatic electrodes}

Glucose dehydrogenase from Aspergillus sp. (FAD-GDH, EC 1.1.99.10 with specific activity $>625 \mathrm{U} \mathrm{mg}^{-1}$ ), was purchased from Sekisui Diagnostics (UK product GLDE-70-1192). The enzyme bilirubin oxidase 'Amano-3' from Myrothecium (BOx, EC 1.3.3.5 with specific activity $\approx 2.5 \mathrm{U} \mathrm{mg}^{-1}$ ) was a generous donation from Amano Enzyme Inc. (Japan).

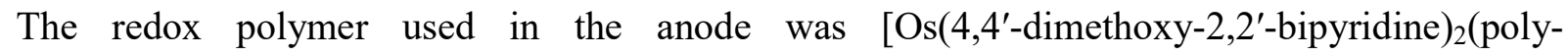
vinylimidazole) $\left.{ }_{10} \mathrm{Cl}\right]^{+}$(Taylor et al., 1995 and Mano and Heller, 2003), (abbreviated to Os(dmobpy)PVI) and the cathode was $\left[\mathrm{Os}\left(2,2^{\prime} \text {-bipyridine }\right)_{2}\right.$ (polyvinylimidazole) $\left.{ }_{10} \mathrm{Cl}\right]^{+}$(abbreviated to Os(bpy)PVI) (Taylor et al., 1995; Mano and Heller, 2003). These mediators were synthesized according to previously published procedures (Forster and Vos, 1990; Ju and Leech, 1997; Conghaile et al., 2013; Kavanagh and Leech, 2013; Cardoso et al., 2014).

Carbon paper electrodes from Fuel Cell Earth (type TG-H-060) were used to immobilize the bioelectrocatalytic solutions. Modification of electrodes with catalyst and mediator was achieved by drop-coating onto $20 \mathrm{~mm}^{2}$ carbon paper surface a mixture of $4.8 \mu 1$ of the corresponding enzyme, GDH or BOx (with a concentration of $10 \mathrm{mg} \mathrm{ml}^{-1}$ in deionized water), $9.6 \mu \mathrm{l}$ $\left(5 \mathrm{mg} \mathrm{ml}^{-1}\right)$ of the redox mediator Os(dmobpy)PVI or Os(bpy)PVI, $2 \mu 1$ of the crosslinker poly(ethylene glycol)diglycidyl ether (PEGDGE) that was prepared in water before its use in a concentration of $15 \mathrm{mg} \mathrm{ml}^{-1}$ and $9.6 \mu \mathrm{l}$ of a $46 \mathrm{mg} \mathrm{ml}^{-1}$ dispersion of multi-walled carbon nanotubes (MWCNT, Sigma), that were previously acid-treated (MacAodha et al., 2013), in distilled water Finally, the electrodes were kept overnight at room temperature (approximately $24{ }^{\circ} \mathrm{C}$ ) until the enzymatic-ink was completely dried.

\subsection{Fuel cell design and fabrication}

\subsubsection{Fuel cell design and fabrication}

The device construction is described in two sections: the fuel cell system core consisting of the electrodes and the paper channel, and the device packaging which is fabricated with the addition of several layers of laser-cut laminated plastic materials. 


\subsubsection{The core of the fuel cell}

The paper fuel cell developed in this work is intended to be fed using biological samples, which limits significantly the available volume of fuel. It is clear that this depends strongly on the nature of the sample to be used; a blood drop coming from a finger prick ranges from $0.3 \mu 1$ to $50 \mu 1$ whereas urine or saliva yields samples in the range of milliliters. As the objective of this study is to evaluate the energy contained in a small quantity of sample and leave it open to potential uses in blood, the volume of the experiments has been limited to $35 \mu 1$.

First, the liquid absorption capacity of 1 Chr paper (from Whatman ${ }^{\circledR}$ ) was tested experimentally by dropping $20 \mu \mathrm{l}$ of an aqueous blue dye several times on a paper sample and measuring the area wetted by the drops. The average area covered by the drops was $310 \pm 30 \mathrm{~mm}^{2}$. Taking this value into account and a paper thickness of $0.18 \mathrm{~mm}$ we set the paper substrate inside the fuel cell to a surface of $5.4 \mathrm{~cm}^{2}$ (fuel cell core) which corresponds to a sample volume of approximately $35 \mu 1$.

The main structure of the device is shown in Fig. 1. (a) and consists of a $35 \mathrm{~mm}$ length and $5 \mathrm{~mm}$ width of $1 \mathrm{Chr}$ paper strip and the two carbon paper electrodes. The paper strip had a circular reception zone of $10 \mathrm{~mm}$ diameter and a $10 \mathrm{~mm}$ x $5 \mathrm{~mm}$ absorption region. A pair of transparent PSA (pressure-sensitive adhesive) layers with a thickness of $75 \mu \mathrm{m}$ and dimensions of $30 \times 15 \mathrm{~mm}^{2}$ (bottom) and $17 \times 15 \mathrm{~mm}^{2}$ (top), were added to the assembly to maintain the elements together. They were cut to different lengths to allow for reception of sample and the absorption of excess liquid during the performance of the experiments. The PSA layers also define the active electrode area $\left(4 \times 5 \mathrm{~mm}^{2}\right)$ exposed to the paper substrate. Carbon paper electrodes were manually cut with dimensions of $5 \times 15 \mathrm{~mm}^{2}$ and modified with the appropriate catalyst. However, the rest of components of the fuel cell, the plastic layers and the paper strip, were cut with a computer controlled $\mathrm{CO}_{2}$ laser engraver (Epilog Mini 24) ( Yuen and Goral, 2010; SpicarMihalic et al., 2013). 
(a)

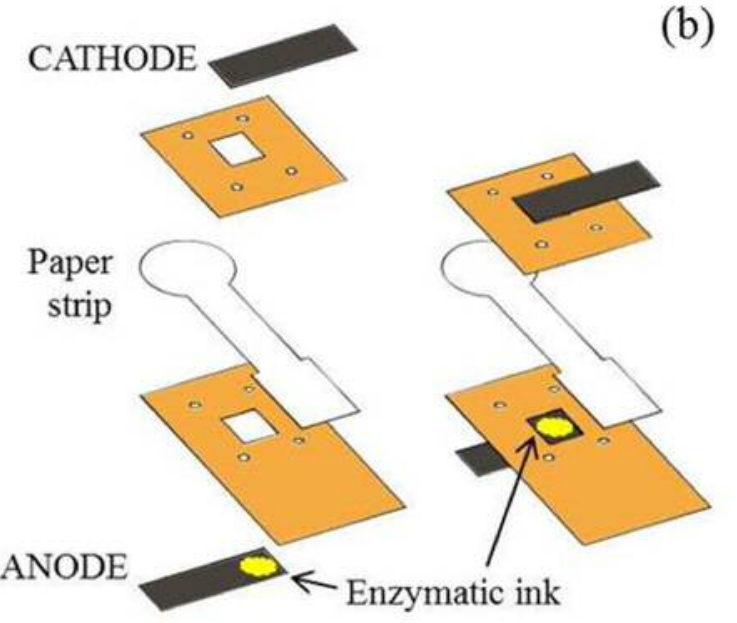

(b)

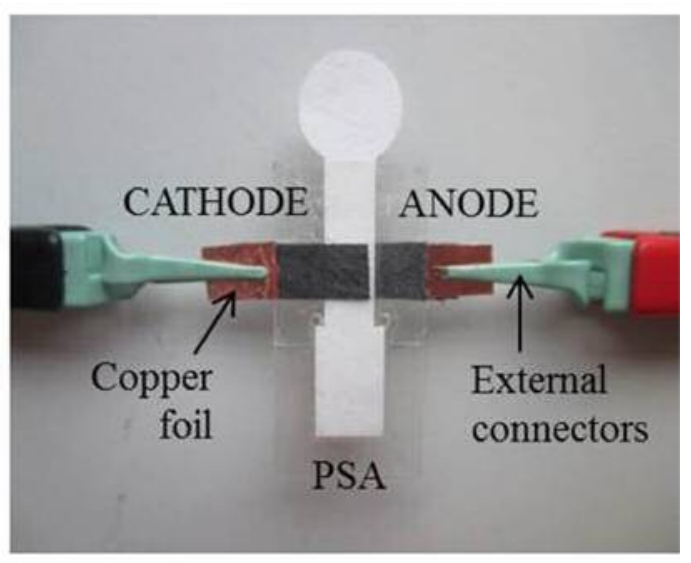

FIG. 1. (a) Depiction of the layers defining the core of the microfluidic paper fuel cell. (b) Photograph of the paper-based microfluidic fuel cell with external electrical connections.

The different components of the fuel cell were aligned and assembled with a four-pin PMMA (poly(methyl methacrylate)) holder. The external connections, see Fig. 1 (b), were accomplished using a section of copper foil clamped around the ends of the carbon electrodes. The fuel cell core was further packaged with layers of laminated materials in order to prevent evaporation of liquid and provide robustness to the device.

\section{Fuel cell packaging}

The fuel cell packaging was fabricated by incorporating multiple layers of laminated adhesive plastic materials to the previously assembled system. Each layer of $25 \times 35 \mathrm{~mm}^{2}$ presents different functions and characteristics. A scheme of the different components of the final device is displayed in Fig. 2. (a) indicating the layers with a number. Layer 1 was fabricated to supply primary backing to the fuel cell. The carbon paper anode was carefully placed over layer 2 . Layer 3, with an open window of $5 \times 4 \mathrm{~mm}^{2}$, defines the active surface of the anode. Layer 4 houses the paper strip with $2.5 \mathrm{~cm}$ of length and final surface area of $5.4 \mathrm{~cm}^{2}$. Layer 5 , like layer 3 , has an aperture of $5 \times 4 \mathrm{~mm}^{2}$ to define the active area of the cathode. Copper foil for the electrical connections was placed at layers 3 and 5 . The cathode, with dimensions of $8 \times 10 \mathrm{~mm}^{2}$, was enclosed in the slot of layer 6 that at the same time was in contact with the copper foil 
attached to the previous layer. Finally, layer 7 closes the entire system while providing several slots to allow the electrode, which is in contact with this layer, to become air-breathing. This is because the porous nature of the electrode material allows it to take oxygen directly from the air, to be reduced at the cathode side.(Jayashree et al. 2005)

All these components were aligned with an external PMMA holder for finally obtaining the device presented in Fig. 2. (b) with a thickness of around $2 \mathrm{~mm}$, see Fig. 2. (c). Electrical connections, with PMMA plugs, allowed connection of the fuel cell during its characterization.

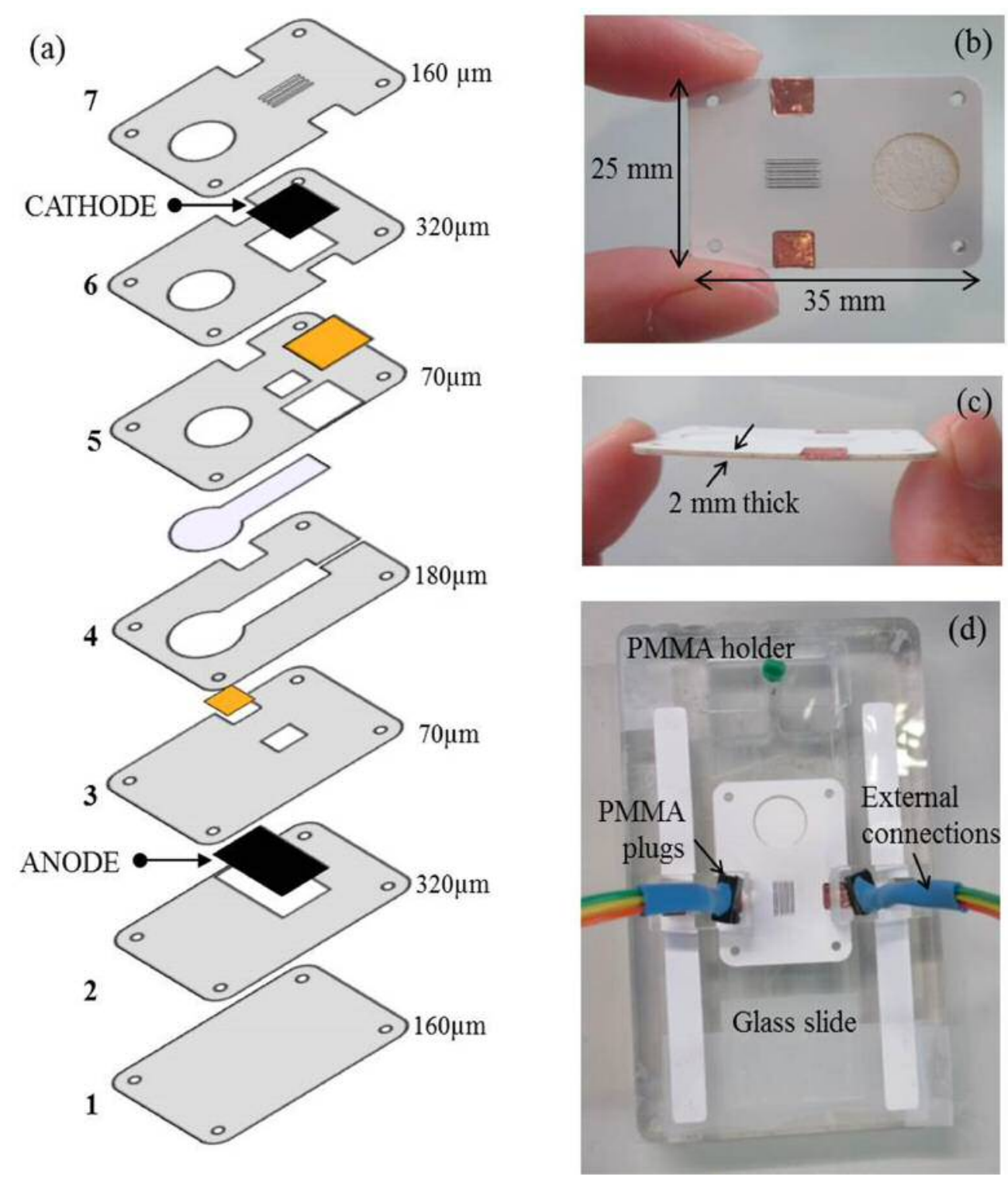

FIG. 2. (a) Scheme of the individual layers forming the packaged microfluidic paper-based 
device. Numbers from 1 to 8 indicate the layer number whereas figures in $\mu \mathrm{m}$ account for the layer thickness. (b) Front-view of the sealed paper device. (c) Side-view of the paper fuel cell. (d) External connections using a PMMA holder.

All these components were aligned with an external PMMA holder for finally obtaining the device presented in Fig. 2. (b) with a thickness of around $2 \mathrm{~mm}$, see Fig. 2. (c). Electrical connections, with PMMA plugs, allowed connection of the fuel cell during its characterization.

\section{Results and discussion}

\subsection{Fuel cell performance at different glucose concentrations}

The sample used to test the fuel cell consisted of $100 \mathrm{mM}$ phosphate buffered saline (PBS) with different amounts of glucose, ranging from 2.5 to $100 \mathrm{mM}$ (the value of high glucose concentrations was used to compare the performance of this fuel cell with other fuels cells reported in the literature). Tests were performed once the sample filled the strip, therefore the fluid was not moving during measurements. For convenience, some of the experiments have been performed using the fuel cell shown in Fig. 1(b). After each measurement, the tested sample was washed out from the paper by placing an absorbent pad at the end of the device whereas at the same time, a new sample was applied at the device entrance. The open circuit potential of the fuel cell was allowed to stabilize after sample renewal for at least $300 \mathrm{~s}$. Then, a slow I-V scan $\left(1 \mathrm{mV} \mathrm{s}^{-1}\right)$ was performed in order to obtain polarization curves.

The paper fuel cell displayed a stable OCP value of $0.65 \mathrm{~V}$ for all measurements, as shown in Fig. 3(a), with variations as low as $\pm 0.05 \mathrm{~V}$. Polarization curves showed a similar slope over the linear region (ohmic losses region) and maximum current achieved by each of the tested samples was clearly dependent on the glucose concentration up to a response saturation at $50 \mathrm{mM}$ of glucose, a value well above the glucose range that can be found in real blood samples. The power generated in the tested glucose concentrations ranged from 20 to $90 \mu \mathrm{W} \mathrm{cm}{ }^{-2}$. The power density generated at the concentration of saturation was $97 \mu \mathrm{W} \mathrm{cm}$ which is the largest power density generated to date by a paper-based device.. 

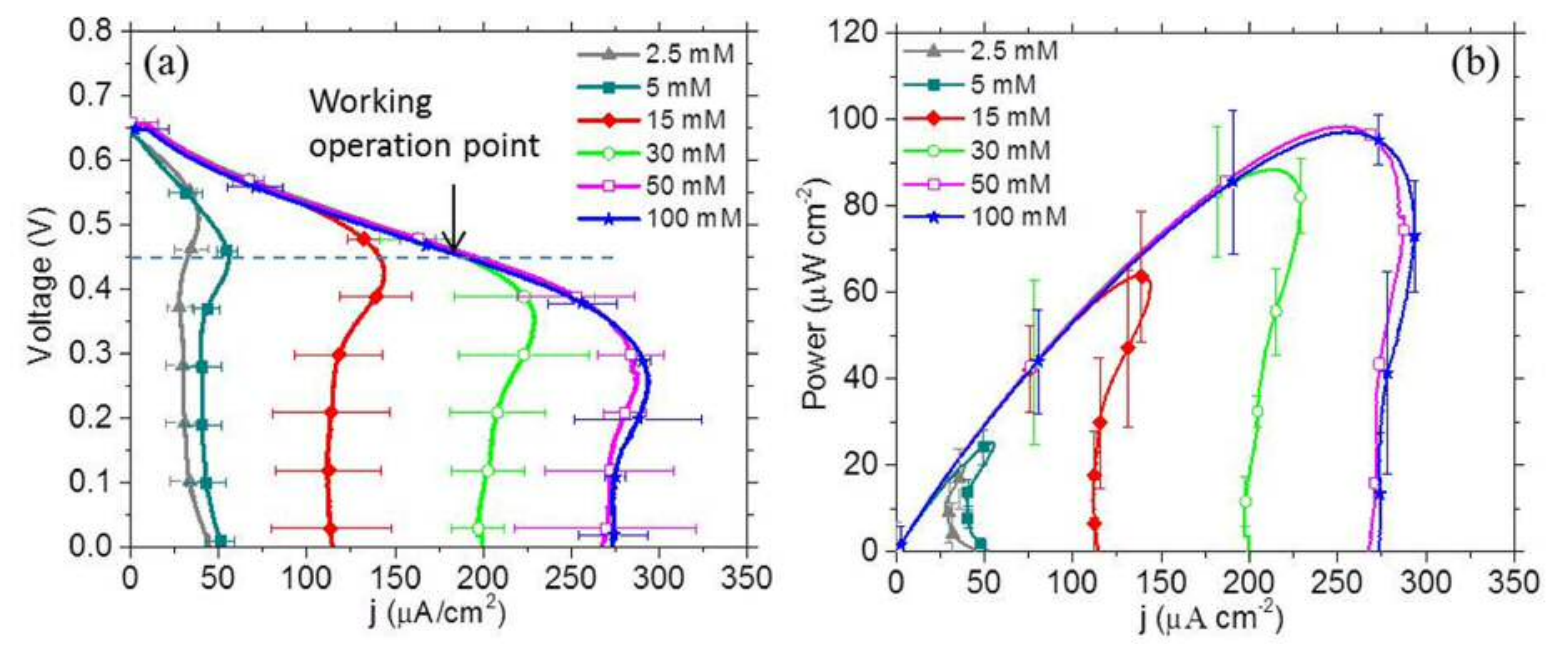

FIG. 3. (a) Polarization and (b) power curves of the microfluidic paper-based fuel cell at different glucose concentrations ranging from $2.5 \mathrm{mM}$ glucose to $100 \mathrm{mM}$ glucose. Error bars represent the standard deviation for three identical experiments.

\subsection{Energy generation at a fixed voltage}

The electrical power that can be extracted from the paper-based fuel cell at a given glucose concentration can be measured by recording the current delivered by the fuel cell when its potential is fixed at a certain value (Nie et al., 2010) In order to obtain the maximum energy efficiency, the fuel cell voltage should be set as near as possible to the $\mathrm{P}_{\max }$ (P-I curves) but without reaching the fuel cell concentration loss region in the polarization curves. In the present case, the operating voltage was set to $0.45 \mathrm{~V}$ and the output current recorded, Fig. 4, over $300 \mathrm{~s}$ for glucose concentrations ranging between 2.5 and $30 \mathrm{mM}$. The curves started with a large current attributed to an initial consumption of reagent, followed by decay due to the appearance of the corresponding diffusion layer. It has to be noted that the current generated by the fuel cell at different concentrations is proportional to the glucose concentration.. 


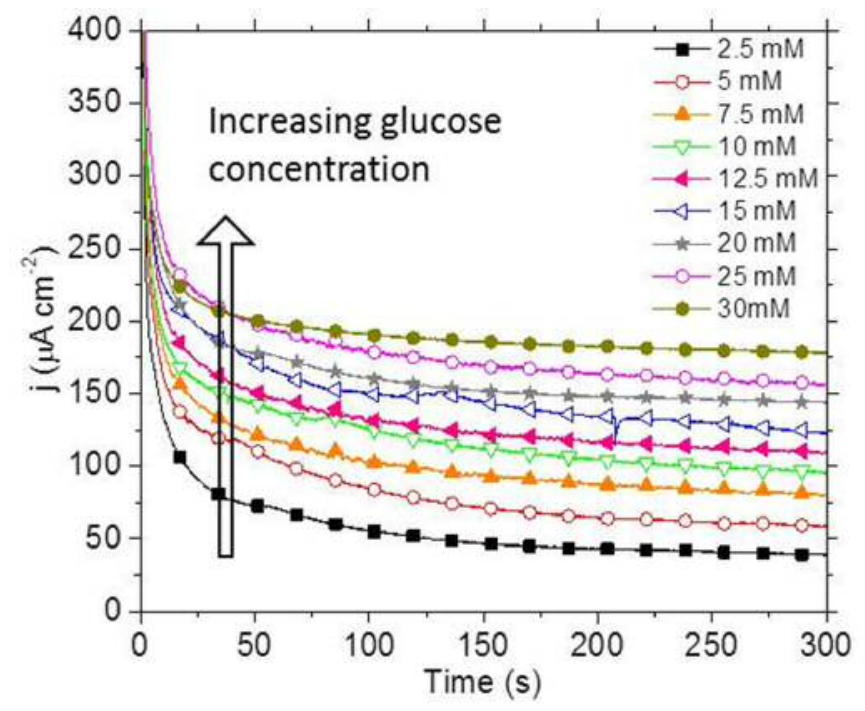

FIG. 4. Representative chronoamperometric curves of the enzymatic paper-based fuel cell working with a fixed volume of sample and a constant potential of $0.45 \mathrm{~V}$. This figure represents the best results of a total of three identical biofuel cells.

Once the $i(t)$ curves were recorded the accumulated energy obtained from each glucose concentration were achieved by integrating the area under the curves using equation 1 .

$$
E=V \int_{0}^{t_{m}} j(t) \cdot d t
$$

The accumulated energy was computed for the first $300 \mathrm{~s}$ of measurement and obtained values were plotted as a function of the glucose concentration in Fig. 5. In order to test the reproducibility of our results, we tested three different fuel cells. The energy obtained from the samples ranged from 1.5 to $3 \mathrm{~mJ}$ with a linear range from $2.5 \mathrm{mM}$ to approximately $15 \mathrm{mM}$ glucose (which covers the typical glucose concentrations present in blood). From here, the average response obtained from the tested devices reached a plateau. This is due to the large data dispersion recorded in the region of 15-30 mM. The variability of the obtained data is attributed to the variations introduced by the manual deposition process used to modify the electrodes with the enzymatic catalytic solution. The average of net power generated during the measurement time is also depicted in Fig. 5. Values range from $12.5 \mu \mathrm{W}$ (at the lowest glucose concentration) to $28.5 \mu \mathrm{W}$ at $15 \mathrm{mM}$. It has to be noted that 
these values yield within the range of power consumption required to operate low-power electronics instrumentation which generally includes analog front-end, processor and communication modules Advances in process technology and integrated circuit design have led to highly energy efficient electronics; some instrumentation amplifiers require as low as hundreds of $\mathrm{nW}$ (Bohorquez et al., 2011), an 8-bit processor consumes in the order of picojoules per instruction at voltages below $0.5 \mathrm{~V}$ (Zhai et al., 2006) whereas the standard IEEE802.15.6 for wireless communication requires few nJ per transmitted bit (Wong et al., 2012). This clearly opens the possibility of using this in-vitro glucose fuel cell as power source for low-consumption diagnostic devices..

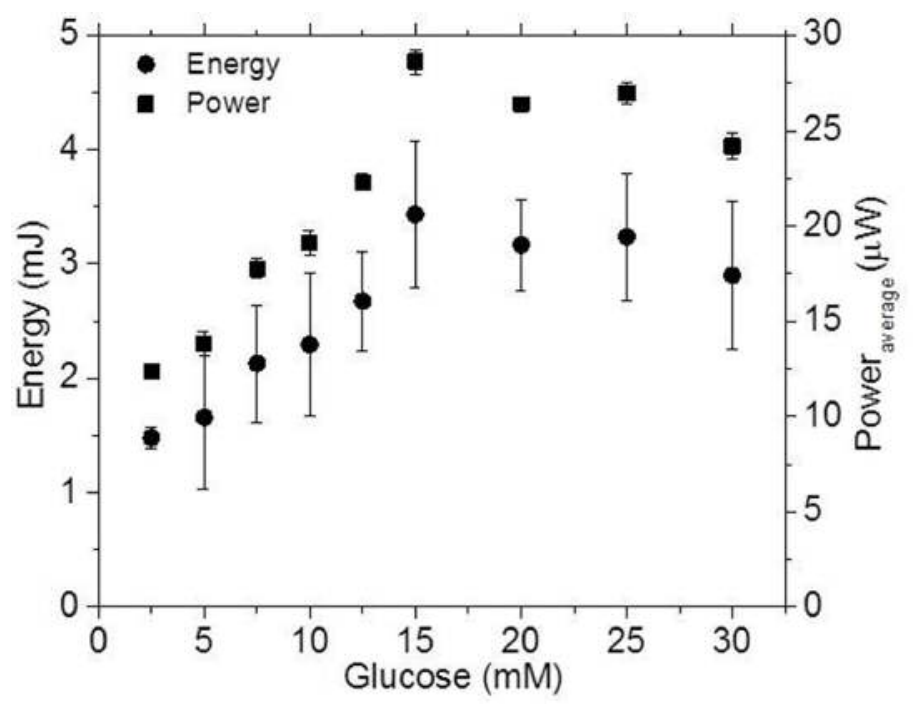

FIG. 5. Energy accumulated during 120 seconds of experiment in a fuel cell made of $1 \mathrm{Chr}$ paper material. The standard deviations correspond to three identical experiments.

\section{Conclusions}

In this work an enzymatic paper-based fuel cell applicable to the development of, flexible, portable and ubiquitous energy devices was presented. The combination of enzymes and mediators allowed the fuel cell to be operated with one solution stream at neutral $\mathrm{pH}$.

The microfluidic system was composed of several layers of laminate adhesive plastic materials, at the end a compact device of $35 \mathrm{~mm} \times 25 \mathrm{~mm}$ and $2 \mathrm{~mm}$ thick was obtained. 
Carbon paper electrodes have been used to deposit a mixture of FAD-GDH enzyme and the redox polymer Os(dmobpy)PVI for the anode and bilirubin oxidase enzyme and the mediator Os(bpy)PVI at the cathode side. The electrodes were combined together in the paper-based fuel cell and the performance of the device was studied for $1 \mathrm{Chr}$ paper substrate which only needed $35 \mu 1$ of sample volume to function. The energy generated from the paper fuel cells was evaluated at a fixed voltage (of $0.45 \mathrm{~V}$ ) and different concentrations of glucose, displaying a linear range for concentrations up to $15 \mathrm{mM}$. However, the values of energy extracted from different devices presented a high variability. This variability is probably due to the low repeatability in the manual process of electrode deposition. The amplitude of the error bars could be diminished by the use of a more reliable process such as screen- or inkjet printing.

The ability to work at neutral $\mathrm{pH}$ and with low volume of sample opens the possibility to work with physiological samples although lower energy values are expected when operating with whole human blood as reported for enzymatic fuel cells in other case scenarios (Conghaile et al., 2016). However, it is important to stress that the linear range that the fuel cell presented in terms of output energy allow for the quantification of glucose in blood within the range of medical interest $(2.5-15 \mathrm{mM})$. This opens the possibility of envisaging a self-powered glucose sensor, which would have an impact on the in-vitro devices domain.

\section{ACKNOWLEDGMENTS}

Peter Ó Conghaile is thanked for synthesis of the redox polymers. Neus Sabaté acknowledges funding from the European H2020 Framework Programme (Grant Agreement 648518 SUPERCELL - ERC 2014 CoG). Juan Pablo Esquivel would like to thank the support from Marie Curie International Outgoing Fellowship (APPOCS) within the 7th European Community Framework Programme. F. Javier del Campo acknowledges funding from the Spanish Ministry of Economy through the DADDi2 project (TEC2013-48506-C3). Dónal Leech acknowledges support from Grant number 607793 under the Bioenergy FP7-PEOPLE-2013-ITN Programme. 


\section{REFERENCES}

2015. Epilog Laser CO2 Laser Systems.

S. Aquino Neto and A. R. De Andrade, 2013. J. Braz. Chem. Soc. 24, 1891-1912.

A. J. Bandodkar and J. Wang, 2016. Electroanalysis.

R. A. Bullen, T. C. Arnot, J. B. Lakeman and F. C. Walsh, 2006. Biosens. Bioelectron. 21(11), 20152045 .

F. Cardoso, S. A. Neto, L. Crepaldi, S. Nikolaou, V. Barros and A. De Andrade, 2014. J. Electrochem. Soc. 161(4), F445-F450.

A. E. Cass, G. Davis, G. D. Francis, H. A. O. Hill, W. J. Aston, I. J. Higgins, E. V. Plotkin, L. D. Scott and A. P. Turner, 1984. Anal. Chem. 56(4), 667-671.

D. M. Cate, J. A. Adkins, J. Mettakoonpitak and C. S. Henry, 2014. Anal. Chem. 87(1), 19-41.

J. Colomer-Farrarons, P. Miribel-Català, A. Saiz-Vela, M. Puig-Vidal and J. Samitier, 2008. IEEE Transactions on Industrial Electronics 55(9), 3249-3257.

J. Colomer, P. Miribel-Català, A. Saiz-Vela, I. Rodríguez and J. Samitier, 2009. A low power CMOS biopotentiostat in a low-voltage $0.13 \mu \mathrm{m}$ digital technology. Midwest Symposium on Circuits and Systems, pp. 172-175.

P. Ó. Conghaile, S. Kamireddy, D. MacAodha, P. Kavanagh and D. Leech, 2013. Anal. Bioanal. Chem. 405(11), 3807-3812.

W. Dungchai, O. Chailapakul and C. S. Henry, 2009. Anal. Chem. 81(14), 5821-5826.

M. Falk, Z. Blum and S. Shleev, 2012. Electrochimica Acta 82, 191-202.

M. Falk, D. Pankratov, L. Lindh, T. Arnebrant and S. Shleev, 2014. Fuel Cells 14(6), 1050-1056.

R. J. Forster and J. G. Vos, 1990. Macromolecules 23(20), 4372-4377.

J. W. Gallaway and S. A. Calabrese Barton, 2008. J. Am. Chem. Soc. 130(26), 8527-8536.

I. Ivanov, T. Vidaković-Koch and K. Sundmacher, 2010. Energies 3(4), 803-846.

R. S. Jayashree, L. Gancs, E. R. Choban, A. Primak, D. Natarajan, L. J. Markoski and P. J. Kenis, 2005. J. Am. Chem. Soc. 127(48), 16758-16759.

H. X. Ju and D. Leech, 1997. Anal. Chim. Acta 345(1-3), 51-58.

C. Jurysta, N. Bulur, B. Oguzhan, I. Satman, T. M. Yilmaz, W. J. Malaisse and A. Sener, 2009. J. Biomed. Biotechnol. 2009, 6.

P. Kavanagh and D. Leech, 2013. Phys. Chem. Chem. Phys. 15(14), 4859-4869. 
J. Kim, H. F. Jia and P. Wang, 2006. Biotechnol. Adv. 24(3), 296-308.

J. w. Lee and E. Kjeang, 2010. Biomicrofluidics 4(4), 041301.

H. R. Luckarift, P. B. Atanassov and G. R. Johnson, 2014. Enzymatic Fuel Cells: From Fundamentals to Applications. Wiley.

D. MacAodha, P. Ó. Conghaile, B. Egan, P. Kavanagh and D. Leech, 2013. Chemphyschem 14(10), 2302-2307.

D. MacAodha, M. L. Ferrer, P. Ó. Conghaile, P. Kavanagh and D. Leech, 2012. Phys. Chem. Chem. Phys. 14(42), 14667-14672.

N. Mano and A. Heller, 2003. J. Electrochem. Soc. 150(8), A1136-A1138.

A. W. Martinez, S. T. Phillips, G. M. Whitesides and E. Carrilho, 2009. Anal. Chem. 82(1), 3-10.

M. T. Meredith and S. D. Minteer, 2012. Annual Review of Analytical Chemistry, Vol 5 5, 157-179.

R. D. Milton, K. Lim, D. P. Hickey and S. D. Minteer, 2015. Bioelectrochemistry 106, Part A, 56-63.

M. J. Moehlenbrock, M. T. Meredith and S. D. Minteer, 2011. ACS Catalysis 2(1), 17-25.

T. H. Nguyen, A. Fraiwan and S. Choi, 2014. Biosens. Bioelectron. 54, 640-649.

Z. Nie, C. A. Nijhuis, J. Gong, X. Chen, A. Kumachev, A. W. Martinez, M. Narovlyansky and G. M. Whitesides, 2010. Lab on a Chip 10(4), 477-483.

P. Ó Conghaile, M. Falk, D. MacAodha, M. E. YAKOVLEVA, C. Gonaus, C. K. Peterbauer, L. Gorton, S. Shleev and D. Leech, 2016. Analytical chemistry.

I. Osadebe, P. Ó. Conghaile, P. Kavanagh and D. Leech, 2015. Electrochimica Acta 182, 320-326.

J. L. Osborn, B. Lutz, E. Fu, P. Kauffman, D. Y. Stevens and P. Yager, 2010. Lab on a Chip 10(20), 2659-2665.

M. H. Osman, A. A. Shah and F. C. Walsh, 2011. Biosens. Bioelectron. 26(7), 3087-3102.

P. Pinyou, F. Conzuelo, K. Sliozberg, J. Vivekananthan, A. Contin, S. Pöller, N. Plumeré and W. Schuhmann, 2015. Bioelectrochemistry 106, 22-27.

S. Rengaraj, V. Mani, P. Kavanagh, J. Rusling and D. Leech, 2011. Chemical Communications 47(43), 11861-11863.

H. Sakai, T. Nakagawa, Y. Tokita, T. Hatazawa, T. Ikeda, S. Tsujimura and K. Kano, 2009. Energy Environ. Sci. 2(1), 133-138.

P. Spicar-Mihalic, B. Toley, J. Houghtaling, T. Liang, P. Yager and E. Fu, 2013. J. Micromech. Microeng. 23(6).

C. Taylor, G. Kenausis, I. Katakis and A. Heller, 1995. J Electroanal Chem 396(1), 511-515. 
N. K. Thom, G. G. Lewis, M. J. DiTucci and S. T. Phillips, 2013. RSC Advances 3(19), 6888-6895.

S. Tsujimura, S. Kojima, K. Kano, T. Ikeda, M. Sato, H. Sanada and H. Omura, 2006. Biosci. Biotechnol. Biochem. 70(3), 654-659.

D. Wen and A. Eychmüller, 2016. Small, n/a-n/a.

P. K. Yuen and V. N. Goral, 2010. Lab on a Chip 10(3), 384-387.

M. Zhou, 2015. Electroanalysis 27(8), 1786-1810. 